\title{
EXCELÊNCIA EM GESTÃO FINANCEIRA: ESTRATÉGIAS, DESAFIOS E OPORTUNIDADES
}

\author{
EdioPolacinski1 ${ }^{1}$ Guilherme Buzanello², Marcos Rogério \\ Rodrigues ${ }^{3}$, Nedisson Luis Gessi ${ }^{4}$
}

\begin{abstract}
RESUMO: 0 mercado financeiro brasileiro está em constante oscilação e, nos últimos anos, identificam-se diversos produtos tanto de renda fixa quanto renda variável. Percebe-se que o mercado indica com algumas incertezas, bem como, com outras oportunidades. Neste contexto, o artigo teve como objetivo analisar o mercado financeiro brasileiro, apresentando estratégias, oportunidades e desafios para alcançar a excelência na gestão financeira. Observe-se que, com base neste estudo, é possível comparar tipos de investimentos demonstrando algumas opções do mercado financeiro com o intuito de auxiliar a tomada de decisão do investidor. Para tanto, abordou-se no referencial teórico, o Sistema Financeiro Nacional, explicando sobre seus principais órgãos, posteriormente, descreveu-se sobre o mercado de ações, um universo muito amplo e cheio de oportunidades e, por fim, apresentaram-se as aplicações financeiras, demonstrando seus principais produtos disponíveis no mercado. A metodologia utilizada foi uma pesquisa teórica empírica, descritiva, explicativa e comparativa, buscando ampliar o conhecimento sobre mercado financeiro, bem como realizando comparações entre produtos financeiros e demonstrando seus possíveis retornos, demonstrando detalhes sobre as opções disponíveis. Segundo a pesquisa, percebeu-se um maior retorno através das ações, do que produtos de renda fixa, porém, é necessário considerar riscos. Dentre todos os resultados, destacam-se os relacionados a Petrobrás, que apresentaram os maiores rendimentos, no período de análise.
\end{abstract}

Palavras-chave: Mercado Financeiro. Investimentos. Riscos. Excelência. Gestão.

Submissão: $17 / 06 / 2020$

Aceite: 06/07/2020

DOI:10.47591/RAC.2674-9203.2020v2n2.art3-32-49

Este trabalho está licenciado com uma Licença Creative Commons Atribuição-NãoComercial 4.0 Internacional.

\footnotetext{
${ }^{1}$ Doutor em Engenharia da Produção pela UFSC. Docente na UFSM, Campus de Palmeira das Missões. Email: edio.pk@gmail.com

${ }^{2}$ Graduação em Ciências Contábeis pela Fundação Educacional Machado de Assis (FEMA). E-mail: guibuzabr@hotmail.com

${ }^{3}$ Mestre em Administração pela Universidade do Vale do Rio dos Sinos (UNISINOS). Professor na Fundação Educacional Machado de Assis (FEMA). E-mail: marcosrodrigues@fema.com.br

${ }^{4}$ Doutor em Desenvolvimento Regional pela Universidade Regional do Noroeste do Estado do Rio Grande do Sul (Unijuí). Professor e Coordenador da Fundação Educacional Machado de Assis (FEMA). E-mail: nedisson@fema.com.br
} 


\section{INTRODUÇÃO}

0 mercado financeiro apesar de estar apresentando algumas oscilações, exibe várias oportunidades de investimento, quase que diariamente. Vale ressaltar que com a intenção de crescimento constante, investidores buscam, neste mercado, a cada dia uma oportunidade para o sucesso. Partindo dessas premissas, definiu-se o objetivo de pesquisa que foi: analisar o mercado financeiro brasileiro, apresentando estratégias, oportunidades e desafios para alcançar a excelência na gestão financeira.

Inicialmente, torna-se importante destacar que os produtos bancários são o jeito mais "fácil" do investidor leigo realizar um aporte, visto que tem grande suporte de seu gerente de conta, onde o mesmo identifica o perfil de investidor do cliente lhe oferecendo investimentos através de analises de perfis individuais. Os produtos bancários são atrativos, mas não quer dizer que sejam as melhores oportunidades que o consumidor possui, pois, atualmente, há uma enorme diversidade de investimentos que podem gerar ônus (ASSAF NETO, 2014).

Além disso, observe-se que as corretoras de valores estão mais acessíveis, pois operam via internet e já disponibilizam taxas de corretagem e custódia a preços muito acessíveis, ou até a taxa zero para algumas operações, e em poucos passos, o investidor consegue realizar investimentos de inúmeros tipos, como a compra de frações do tesouro Selic, aportar em fundos de investimento, ou até comprar ações. Para que isso seja realizado, apenas é necessário que o "consumidor" realize o cadastro em uma corretora de valores, deposite o dinheiro na conta e faça o investimento (FORTUNA, 2015).

Neste ínterim, acrescente-se que foi realizada uma pesquisa bibliográfica, baseando-se no que preconizam autores e suas respectivas obras, publicadas em livros, revistas, e-books e documentos em geral (Assaf Neto, Deschatre, Cerbasi, Nigro, entre outros). Com base nisso, apresentou-se um conjunto de informações acerca de um conhecimento complementar sobre o mercado financeiro e seus produtos disponíveis.

Ademais, explica-se o funcionamento do mercado financeiro em geral, iniciando com o Sistema Financeiro Nacional para um melhor entendimento acerca do funcionamento do sistema no Brasil. Após, apresenta-se o mercado de ações, onde se explica sobre o mercado de renda variável e, em seguida, citam-se os demais produtos do mercado financeiro brasileiro, seguindo de explicações claras para estes. No decorrer do trabalho, tem-se a comparação entre os diferentes tipos de mercado, de investimentos e de rentabilidade.

Assim, com base no exposto, se espera com esta pesquisa oferecer subsídios de informações acerca da temática proposta aos demais pesquisadores, profissionais da área, bem como investidores em potencial. 


\section{REFERENCIAL TEÓRICO}

\subsection{O SISTEMA FINANCEIRO NACIONAL}

O Sistema Financeiro Nacional (SFN) é de grande importância para a economia e para o bom funcionamento dos recursos do país, pois ele é um conjunto de órgãos que regulamenta, fiscaliza e executa as operações necessárias para circulação da moeda e do crédito na economia (ABREU; SILVA, 2017). O SFN é regido pela lei da reforma bancária de 1964, lei do mercado de capitais em 1965 e lei de criação dos bancos múltiplos em 1988, ele é estruturado e conta com todas as instituições financeiras, considerando as públicas ou privadas que existem no país. O sistema é regulado através de dois grandes subsistemas, o normativo e intermediação financeira (ASSAF NETO, 2014).

O SFN tem sua formação de acordo com entidades/instituições, estas que promovem a intermediação financeira, que é a junção dos credores e tomadores de recursos. Através do SFN, empresas, governo e pessoas físicas possuem movimentações sobre seus ativos, realizam investimentos e quitam dívidas (BACEN, 2019a). Além disso, destaque-se:

Subsistema normativo, ainda existem três outras instituições financeiras atuando em caráter especial, são elas: o Banco do Brasil (BB), Banco Nacional de Desenvolvimento Econômico (BNDES) e, por fim, a Caixa Econômica Federal (CEF). (ASSAF NETO, 2014, p. 41).

A segunda explicação fica por conta das intermediações financeiras, que são classificadas em bancárias e não bancárias. Estas se classificam, basicamente, na capacidade ou não de emitir moeda. As ramificações do sistema financeiro nacional são constituídas por instituições, sobre o subsistema normativo, Assaf Neto afirma que:

É constituída por instituições que estabelecem, de alguma forma, diretrizes de atuação das instituições financeiras operativas e controle do mercado. Compõe esse subsistema o Conselho Monetário Nacional, o Banco Central do Brasil, a Comissão de Valores Mobiliários, o Banco do Brasil, o Banco Nacional de Desenvolvimento Econômico e Social, e a Caixa Econômica Federal. (ASSAF NETO, 2014, p. 43).

Sobre o Conselho Monetário Nacional, refere-se a um órgão superior do SFN, tem características únicas que são exemplificadas como formular a política do crédito e da moeda, tendo por base seu objetivo de segurança e estabilidade para a moeda e o desenvolvimento econômico da sua pátria (MINISTÉRIO DA ECONOMIA, 2019).

Para Fortuna (2005), o Conselho Monetário Nacional (CMN) é um órgão normativo, porém não lhe cabem funções executivas. É classificado como a entidade superior do sistema financeiro. Podem-se utilizar como alguns exemplos de serviços do CMN segundo Fortuna: Adaptar o volume dos meios de pagamento às reais necessidades da economia nacional e seu processo de desenvolvimento; Regular o valor interno da moeda, prevenindo ou corrigindo os surtos inflacionários ou 
deflacionários de origem interna ou externa; Regular o valor externo da moeda e o equilíbrio do balanço de pagamentos do País. Abreu e Silva (2017, p. 16-17) citam os objetivos da CMN que estão definidos no artigo $3^{\circ}$ da Lei no 4.595 :

I - Adaptar o volume dos meios de pagamento às reais necessidades da economia nacional e seu processo de desenvolvimento. II - Regular o valor interno da moeda para tanto, prevenindo ou corrigindo os surtos inflacionários ou deflacionários de origem interna ou externa, as depressões econômicas e outros desequilíbrios oriundos de fenômenos conjunturais. III - Regular o valor externo da moeda e o equilíbrio no balanço de pagamento do País, tendo em vista a melhor utilização dos recursos em moeda estrangeira. IV - Orientar a aplicação dos recursos das instituições financeiras quer públicas, quer privadas; tendo em vista propiciar, nas diferentes regiões do País, condições favoráveis ao desenvolvimento harmônico da economia nacional. V - Propiciar o aperfeiçoamento das instituições e dos instrumentos financeiros, com vistas à maior eficiência do sistema de pagamentos e de mobilização de recursos. VI - Zelar pela liquidez e solvência das instituições financeiras. VII - Coordenar as políticas monetária, creditícia, orçamentária, fiscal e da dívida pública, interna e externa.

Brito afirma sobre o conselho monetário: Compete a CMN traçar as normas de política monetária em todos os seus aspectos. Funciona como um conselho da economia brasileira e supervisiona as políticas monetárias, cambial, de investimento, de capital estrangeiro, de comércio exterior e fiscal (BRITO, 2013). De acordo a BACEN (2019b), o Banco Central tem por finalidade a formulação, a execução, o acompanhamento e o controle das políticas monetária, cambial, de crédito e de relações financeiras com o exterior; a organização, disciplina e fiscalização do SFN e do Sistema de Consórcio; a gestão do Sistema de Pagamentos Brasileiro (SPB) e dos serviços do meio circulante. Assaf Neto afirma sobre a intenção do BACEN sobre as instituições:

Atendendo a uma conceituação mais abrangente de sua atuação, pode-se tratar o Banco Central como um banco fiscalizador e disciplinador do mercado financeiro, ao definir regras, limites e condutas das instituições, banco de penalidades, ao serem facultadas pela legislação a intervenção e a liquidação extrajudicial em instituições financeiras, e gestor do Sistema Financeiro Nacional, ao expedir normas e autorizações e promover o controle das instituições financeiras e de suas operações. (ASSAF NETO, 2014, p. 44).

Dentre uma das atribuições do Banco Central está a emissão da moeda, após a sua impressão, realizando a entrega do numerário ao sistema bancário. (ASSAF NETO, 2014). Para Fortuna, o Banco Central é essência criada para atuar como órgão executivo central do sistema financeiro nacional (FORTUNA, 2015).

Através de pesquisa diretamente na pagina web da CVM, é possível encontrar a seguinte afirmação: "A Comissão de Valores Mobiliários (CVM) foi criada em 07/12/1976 pela Lei $6.385 / 76$, com o objetivo de fiscalizar, normatizar, disciplinar e desenvolver o mercado de valores mobiliários no Brasil". (CVM, 2019). Segundo Assaf Neto, as funções básicas da CVM podem ser exemplificadas a seguir: 
Promover medidas incentivadoras à canalização das poupanças ao mercado acionário; estimular o funcionamento das bolsas de valores e das instituições operadoras do mercado acionário, em bases eficientes e regulares; assegurar a lisura nas operações de compra e venda de valores mobiliários e promover a expansão de seus negócios; dar proteção aos investidores. (ASSAF NETO, 2014, p. 45).

Para Fortuna, o objetivo da CVM é proteger os investidores, manter a eficiência e a ordem dos mercados e aumentar a facilidade de formação de capital por parte das empresas. Basicamente, a Comissão de Valores Mobiliários em se tratando de bolsa de valores, tem como objetivos fundamentais o fortalecimento do mercado de ações e demais valores mobiliários, estimulando a aplicação de poupança no mercado acionário; garantindo o correto funcionamento das bolsas de valores (FORTUNA, 2015).

De acordo com as informações disponibilizadas, pode-se considerar que o sistema financeiro nacional é um sistema complexo e bem organizado, para que, de todas as formas, mantenha um padrão de funcionamento, para que o estado não tenha prejuízos desnecessários.

\subsection{MERCADO DE AÇÕES}

O investidor pessoa física necessita criar uma conta em uma corretora de valores, para realizar seus investimentos nos produtos do mercado financeiro. Desta forma, pode-se afirmar que uma corretora de valores é uma instituição financeira. Através desta corretora, o cliente ou investidor terá acesso aos tipos de produtos e investimentos disponíveis. Basicamente, a corretora faz a ponte entre o investidor e seu dinheiro aos produtos como Tesouro Selic, Ações, ou Fundos (EASYNVEST, 2019).

Entre o ano de 2002 até a crise de 2008, o mercado financeiro brasileiro apresentou uma rentabilidade de mais de 400\%, e no período de 2008 a 2012 o mercado imobiliário apresentou alta de 124\%. Seja por total desconhecimento ou medo, os brasileiros optaram por manter sua renda estagnada em aplicações pouco rentáveis, tendo como a mais exemplar a poupança (NIGRO, 2018).

Para realizar qualquer tipo de investimento, informação sobre este mercado é essencial. 0 investidor precisa saber em que solo ele está pisando, por isso é necessário conhecimento sobre alguns principais dados que envolvem o mundo do mercado financeiro.

\footnotetext{
Antes de colocar a mão no bolso para fazer sua aplicação é fundamental conhecer esse mercado ou qualquer outro em que você queira investir. Simplesmente porque investir em mercados que você não conhece, não sabe os riscos nem de onde vêm os ganhos, é o primeiro passo para perder dinheiro. (LUQUET; ASSEF, 2007, p. 52).
}

Sobre a tributação e sobre as ações, de acordo a Itau (2019), identifica-se que esses tributos são cobrados sobre o ganho líquido mensal, ou seja, a diferença positiva entre o valor da venda menos o valor da compra e os custos das transações. Logo, só há incidência de IR se o investidor tiver lucro nas operações. Ficam isentos 
de IR os ganhos líquidos obtidos pelo investidor pessoa física, na venda de ações desde que não ultrapasse os R 20 mil/mês. Para operações normais, o investidor paga uma alíquota de IR de $15 \%$ sobre seu ganho, já em operações que se iniciam e terminam no mesmo dia (Day-trade), esta alíquota é de $20 \%$.

Para Assaf Neto, as ações são a menor parcela ou fração do capital social de uma sociedade anônima, são valores negociados e distribuídos aos acionistas de acordo com a participação de cada um (ASSAF NETO, 2014). As pessoas que investem em ações são chamadas de acionistas ou investidores.

O nível de desenvolvimento de uma economia é diretamente proporcional ao grau de atividade de seu mercado de capitais. Nações com alto grau de desenvolvimento econômico geram mais oportunidades para que empresas, indivíduos e instituições apliquem suas poupanças. (DESCHATRE, 2009, p. 31).

Existem algumas vantagens aos investidores que optam por adquirir ações. Neto cita como benefícios os Dividendos, que são uma parte dos resultados da empresa distribuídos aos acionistas, Bonificação, que é a emissão e distribuição aos acionistas, Valorização das ações, e Direito de subscrição, que é quando ocorre do preço fixado pelo mercado àquela ação se apresenta valorizado em relação ao seu preço inicial (ASSAF NETO, 2014).

Na abertura do capital de uma empresa, há a emissão de ações desta, o qual de certa forma torna a representar uma parcela da empresa. Ao entrar no mercado, a empresa realiza o que é chamado de InitialPublicOfferings (IPO), e é disponibilizada para compra. Para Cerbasi, existe a possibilidade de um IPO ser um fracasso caso o preço decidido pela empresa por suas ações for muito elevado, considerado desproporcional, por essas limitações, IPOs não são a melhor alternativa para iniciantes no mercado, porém podem ser ótimas oportunidades para investidores mais experientes (CERBASI, 2008).

\begin{abstract}
A análise fundamentalista é utilizada como forma de avaliação para alternativas de investimento a partir do estudo das informações obtidas junto às empresas, em conjunto com o cenário macroeconômico e os diversos momentos setoriais nos quais as companhias se inserem, passando pela análise de seus balanços e demonstrações financeiras com o intuito de estabelecer previsões para o seu desempenho e calcular seu teórico preço "justo", com o uso de metodologias como a do fluxo de caixa descontado. (MARTINS, 2008, p. 195).
\end{abstract}

Através desta análise, o investidor consegue obter uma ótima noção de como está a saúde financeira e organizacional da empresa, no entendimento de Elder, "Os fatores fundamentais são muito importantes para os operadores em longo prazo, que querem embarcar nas grandes tendências para vários meses ou anos". (ELDER, 2006, p. 39).

Porém, como segunda opção de análise, tem-se a análise gráfica, ou técnica, esta por sua vez caracteriza-se como sendo uma análise baseada em estatísticas e estudo dos próprios gráficos. Esta análise é realizada com base no comportamento de um ativo no mercado, este que pode ser ação, moeda ou commodity. Segundo a 
teoria de Charles Dow, os gráficos espelham o comportamento da "multidão". (LUQUET; ROCCO, 2005, p. 79).

Fica evidente que o ramo de ações e renda variável necessita de um perfil diferenciado de investidor, pois a sua alta volatilidade requer preparo psicológico. Por isso, fica com os ativos de renda variável (ações) um perfil mais arrojado de investidor, o qual não vê muito problema em assumir riscos.

\subsection{APLICAÇÃO FINANCEIRA}

No Brasil, o investimento mais popular é a poupança, caracterizada por ser puramente renda fixa, ela possui uma grande segurança no capital investido, porém com rendimentos limitados e geralmente baixos. A poupança possui uma data de aniversário, que é o dia em que o capital começou a ser investido, e neste dia ela produz seu rendimento. Assaf Neto explica que, os rendimentos são calculados mensalmente e creditados sempre nesta data ao aplicador. Também explica que, caso haja retiradas antes da data de aniversário, a caderneta não paga nenhum rendimento sobre o dinheiro sacado (ASSAF NETO, 2014).

Certos investimentos possuem garantia total de $\mathrm{R} \$ 250.000,00$ por $\mathrm{CPF}$ e por instituição financeira. Quem garante isso é o (FGC) Fundo Garantidor de Crédito. Isso garante que o investidor possua segurança ao aportar seus investimentos em produtos cobertos pelo fundo (RICO, 2019a). Sobre a segurança das aplicações, os saldos aplicados são garantidos, até determinado valor $(\mathrm{R} \$ 250.000,00)$ pelo governo, por CPF (ASSAF NETO, 2014).

Apesar dos juros serem os representantes fidedignos da renda fixa, os mesmos são sujeitos a flutuações significativas ao longo do tempo especialmente no Brasil, cujo governo tenta balizar a atividade econômica através da sua intervenção [...]. Operações com índices de juros costumam ter os maiores volumes dos mercados em que são operadas. (DESCHATRE, 2009, p. 28).

0 investimento no Tesouro Direto oferece títulos com diferentes rentabilidades, são elas: prefixada, ligada à variação da inflação ou variação da taxa de juros básica da economia - Selic (TESOURO DIRETO, 2019). 0 Tesouro Selic é uma opção parecida com a poupança, que tem uma taxa, definida através do Comitê de Políticas Monetárias (INFOMONEY, 2019). O certificado de depósito bancário (CDB), por sua vez, é um título bancário, que pode ser contratado pelo cliente, que tem por característica o resgate, que só será feito ao final do prazo estipulado no contrato (ASSAF NETO, 2014). Sobre o Certificado de Depósito Bancário, Fortuna afirma ser de certa forma um investimento flexível:

O CDB é transferível (resgatado, a critério da instituição financeira, antes do vencimento) por endosso nominativo. Desde que respeitados os prazos mínimos. 0 endossante responde pela existência do credito, mas não pelo seu pagamento. Além disso, não pode ser prorrogado, mas renovado de comum acordo por nova contratação. (FORTUNA, 2015, p. 206). 
As (LCI) Letras de Crédito Imobiliário são títulos emitidos basicamente por bancos e instituições financeiras que pagam ao investidor um valor acordado no momento do investimento, e este se torna fonte de investimentos para o setor imobiliário, sendo lastreados em créditos imobiliários. Na prática, o investidor realiza um empréstimo para o setor imobiliário, este que devolverá o dinheiro corrigido no futuro (BTG PACTUAL, 2019).

Ainda sobre as LCI, o pagamento de juros nesta modalidade de investimento pode ser periódico, ou apenas no vencimento do título, e é vedada a rentabilidade em casos de resgate total ou parcial antes do término do vencimento do título (FORTUNA, 2014). Na opção da (LCA) Letra de Crédito Agrícola, o investidor possui um risco baixo no seu investimento, e taxas de rendimento atrativas.

A LCA é uma excelente opção de investimento para quem busca diversificar o seu patrimônio com aplicações de baixo risco. 0 produto possui isenção de imposto de Renda e IOF para Pessoa Física, o que torna sua taxa equivalente bastante atrativa, podendo apresentar uma rentabilidade competitiva com demais produtos. Para saber mais sobre as condições de negócio fale com seu gerente. Rentabilidade atrelada ao CDI. (SICREDI, 2019).

Sobre os Fundos de Investimento, atualmente existem muitos tipos, com vários graus de risco para a rentabilidade destes, podem ser de renda fixa ou variável. A soma dos investimentos realizados no fundo forma o seu patrimônio, este que é aplicado por uma instituição profissional. Em um fundo as decisões serão refletidas por seus objetivos e políticas pré-definidos. Desta forma, os investimentos tem a chance de serem tanto bem quanto mal sucedidos, havendo a valorização/desvalorização de cotas (INFOMONEY, 2019).

Quando o assunto do fundo é risco, tem-se em mente que quanto maior o risco, mais satisfatório poderá ser o retorno, logo, quanto mais seguro for o fundo, naturalmente a sua rentabilidade será menor. Para Assaf Neto:

Há uma relação direta entre risco e retorno nas aplicações em Fundos de Investimento. Quanto maior a possibilidade de retorno de um fundo, maior será o risco assumido. Fundos que oferecem maior segurança a seus participantes costumam apresentar retorno mais reduzido. (ASSAF NETO, 2014, p. 348).

Sobre a liquidez dos fundos de investimento, afirmar-se de acordo a Assaf Neto, que a maioria destes fundos permite que o cotista saque seus recursos a qualquer momento, obtendo por isso uma liquidez diária em suas aplicações (ASSAF NETO, 2014). Na economia, existem momentos bons e momentos ruins. Estes devem ser identificados no momento certo, e assim, o investidor terá a chance de tirar proveito de ambos. Para Deschatre, sobre as poupanças, percebe-se que:

O nível de desenvolvimento de uma economia é diretamente proporcional ao grau de atividade de seu mercado de capitais. Nações com alto grau de desenvolvimento econômico geram mais oportunidades para que empresas, indivíduos e instituições apliquem suas poupanças. (DESCHATRE, 2009, p. 31). 
De acordo com as informações apresentadas, pode-se entender que fundos de investimento são uma modalidade razoavelmente segura para o investidor, visto que possuem o termômetro de risco que este pode escolher. Os Fundos de Investimento Imobiliário, também conhecidos como FII, permitem ao investidor a compra de parte de bens, que podem ser divididos em fundos de investimento, de tijolo, CRI, papel, fundos que investem em outros fundos e etc., e receber aluguéis/dividendos por estas cotas (ASSAF NETO, 2014).

Fundos de investimento imobiliário são instrumentos de investimento coletivo, cujos recursos são captados no mercado e direcionados a aplicações em ativos (empreendimentos) imobiliários (ASSAF NETO, 2014). Um fundo imobiliário tem seus ganhos de acordo com a receita de locação e alienação de imóveis adquiridos, bem como:

Os ganhos do fundo são geralmente provenientes de receitas de locação e ganhos na alienação de imóveis adquiridos. As locações mais comuns são de salas comerciais e escritórios, prédios comerciais e shopping centers. 0 ganho na alienação é determinado pela valorização do imóvel a venda, sendo o resultado da alienação maior que o valor aplicado em sua aquisição. (ASSAF NETO, 2014, p. 353).

Em uma pequena comparação sobre adquirir um imóvel físico ou um fundo imobiliário, Bastos e Baroni abordam sobre a facilidade de adquirir um FII:

\begin{abstract}
Não é preciso esperar meses ou anos para acumular o capital necessário para aquisição de uma pequena propriedade para locação, nem perder tempo correndo atrás de papelada, conversando com corretores e tentando encontrar um imóvel que torne viável seu investimento. (BASTOS, BARONI, 2018, p. 11).
\end{abstract}

Nigro dá uma breve e clara explicação sobre o que são os FIIs, no qual explica que ao aportar em um fundo imobiliário, ao invés de comprar um imóvel sozinho, o investidor estará se tornando associado a vários investidores que também tem o interesse em comum de entrar no mercado imobiliário (NIGRO, 2018). Ainda, ao realizar este tipo de investimento, fará parte de uma espécie de grupo de investidores, voltados ao ramo imobiliário.

\footnotetext{
São um tipo de ativo negociado em Bolsa que expõe o investidor ao mercado imobiliário. Na verdade, ao investir em um fundo imobiliário, em vez de comprar um imóvel sozinho, você estará se associando a vários outros investidores que também têm interesse em entrar no mercado imobiliário. 0 dinheiro de todos os investidores vai para um fundo, e esse fundo terá como objetivo uma série de compras no mercado imobiliário. (NIGRO, 2018, p. 147).
}

Através das explicações anteriores, pode-se concluir que existem os mais variados tipos de investimento, cada um deles com sua particularidade. Não é possível indicar qual modalidade é em si a melhor, pois quem deverá identificar esta 
parte é o investidor, o qual irá se identificar melhor com a forma de investimento que melhor de adequar ao seu perfil.

\section{MÉTODO}

De acordo com Severino (2000), um ensaio teórico, ou estudo bibliográfico, consiste na exposição lógico-reflexiva com ênfase na argumentação e interpretação pessoal. Com base nisto, saliente-se que o presente estudo pode ser categorizado quanto a sua natureza como uma pesquisa teórica empírica, pois busca a ampliação de conhecimentos sobre o mercado financeiro realizando a comparação entre os tipos de investimentos.

O estudo também pode ser caracterizado por sua finalidade descritiva, por enfocar a descrição das características de determinada população ou fenômeno, ou o estabelecimento de relações entre variáveis (GIL, 1999), neste caso, conceitos e definições.

Considerando o caráter teórico da pesquisa, ressalta-se que a mesma também se utilizou dos princípios do método dialético (SILVA; MENEZES, 2005), a partir do qual as definições foram confrontadas na tentativa de encontrar semelhanças (coerência) e diferenças (inconsistências relativas), no caso em estudo, sobre a diversidade de investimentos e seus possíveis retornos financeiros.

Mais especificamente, saliente-se que para a presente pesquisa optou-se por escolher 3 investimentos de renda variável (ações da Petrobras - Cia Vale do Rio Doce - e Banco do Brasil), também se escolheu investimentos de renda fixa e mais conservadores tais como: certificado de depósito bancário, a poupança, LCA, LCI e Tesouro Selic. Analisou-se o grau de risco de cada tipo de investimento, expondo a rentabilidade de cada um, porém analisando quanto ao seu grau de risco se aquele ativo vale a pena ou não, adequando-se a cada perfil de investidor. 0 período de análise destes investimentos foi no decorrer de 180 dias, ou seja, de 02/01/2019 a 28/06/2019.

Os dados foram analisados considerando-se as abordagens comparativas, descritivas e explicativas. Observe-se que a rentabilidade desses foi demonstrada levando em consideração uma taxa de rendimentos de um período de 12 meses. Posteriormente, foram analisadas durante um período de 6 meses igualmente para todos os ativos, alocando o valor de $\mathrm{R} \$ 5.000,00$ para cada um deles, sendo possível, com base nisso, identificar um parecer sobre o investimento no geral e as diferenças dos dados considerados.

\section{APRESENTAÇÃO DOS RESULTADOS}

Buscando atender ao objetivo do trabalho, elaborou-se uma análise com base numa cesta de investimentos, esta composta por: Poupança, Tesouro Selic 2025, CDB, LCI, LCA, Fundo de Investimento e Ações. Esta carteira, teve acompanhamento durante o período de 6 meses, ou mais precisamente do dia 02/01/2019 e encerrando na data de 28/06/2019. Na Figura 1 é possível ter uma prévia dos tipos de operações realizadas no trabalho. 
Figura 1 - Aplicações

\begin{tabular}{|c|c|c|c|c|c|c|}
\hline $\begin{array}{c}\text { TIPO DA } \\
\text { APLICAÇÃO }\end{array}$ & POUPANÇA & $\begin{array}{l}\text { TESOURO } \\
\text { SELIC } 2025\end{array}$ & CDB & $\mathrm{LCl}$ & LCA & \begin{tabular}{|c} 
FUNDO \\
INVESTIMENTOO
\end{tabular} \\
\hline $\begin{array}{c}\text { CLASSIFICAÇÃO } \\
\text { CVM }\end{array}$ & RENDA FIXA & RENDA FIXA & RENDA FIXA & RENDA FIXA & RENDA FIXA & MULTIMERCADO \\
\hline NIVEL DE RISCO & MUITO BAIXO & MUITO BAIXO & BAIXO & BAIXO & BAIXO & MODERADO \\
\hline APLICAÇÃO INICIAL & NÃO HÁ & $R \$ \quad 104,02$ & $R \$ 1.000,00$ & $R \$ 1.000,00$ & $1.000,00$ & $1.000,00$ \\
\hline $\begin{array}{c}\text { RENTABILIDADE } 12 \\
\text { MESES }\end{array}$ & $4,55 \%$ & $6,50 \%$ & $\begin{array}{c}101 \% \mathrm{DO} \text { CDI } \\
(6,2 \%)\end{array}$ & $\begin{array}{c}97 \% \text { DO CDI } \\
(5,96 \%)\end{array}$ & $\begin{array}{c}100 \% \mathrm{DO} \text { CDI } \\
(6,14 \%)\end{array}$ & $5,37 \%$ \\
\hline $\begin{array}{c}\text { CRÉDITO EM } \\
\text { CONTA CORRENTE }\end{array}$ & IMEDIATO & $D+1$ & $D+2$ & FINAL INVEST. & FINAL INVEST. & $D+1$ \\
\hline $\begin{array}{l}\text { CLASSIFICAÇÃO } \\
\text { TRIBUTÁRIA }\end{array}$ & CURTO PRAZO & MEDIO PRAZO & MEDIO PRAZO & MEDIO PRAZO & MEDIO PRAZO & LONGO PRAZO \\
\hline ADMINISTRADOR & GOVERNO & GOVERNO & $\begin{array}{l}\text { CDB GMAC- } \\
\text { NOV } 2020\end{array}$ & $\begin{array}{l}\text { LCI BANCO } \\
\text { RIBEIRÃO } \\
\text { PRETO }\end{array}$ & BANCO FIBRA S.A. & $\begin{array}{l}\text { BNY Mellon } \\
\text { Serviços } \\
\text { Financeiros } \\
\text { DTVM S.A }\end{array}$ \\
\hline GESTOR & GOVERNO & GOVERNO & $\begin{array}{c}\text { BANCO GMAC } \\
\text { S.A }\end{array}$ & \begin{tabular}{|c|} 
BANCO \\
RIBEIRAO \\
PRETO S.A.
\end{tabular} & BANCO FIBRA S.A. & \begin{tabular}{|c|} 
ARX \\
INVESTIMENTO \\
S LTDA. \\
\end{tabular} \\
\hline
\end{tabular}

Fonte: Rico Corretora (2019b).

Iniciou-se com uma análise da Caderneta de Poupança, investimento pouco rentável, porém com alta liquidez e grande segurança, possui grande popularidade entre a população brasileira, este gerou um ágio de 4,55\% em um investimento de 12 meses, lembrando que esta opção é livre de imposto de renda, o investidor resgata o capital total.

Posteriormente, analisou-se o Tesouro Selic 2025, que é uma modalidade muito parecida com a poupança, porém ainda oferece retornos mais consideráveis e acaba sendo mais atrativo do que a anterior, oferecendo uma rentabilidade de 6,5\% ao ano, uma diferença relevante de 1,95\% se comparado à poupança, desde que o investidor não realize o saque, que é proporcional ao tempo da aplicação.

Fora incluído no trabalho, um Certificado de Depósito Bancário (CDB) cuja empresa administradora é o Banco Chevrolet (GMAC), e constatou-se que nesta modalidade o investidor possui uma forma mais ampla de investimento, porém no que diz respeito a rentabilidade final, no período analisado de 6 meses o mesmo acabou não se destacando, oferecendo, um rendimento razoavelmente baixo de $6,2 \%$ ao ano.

Analisou-se a Letra de Crédito Imobiliário (LCI), este tendo como gestor o Banco Ribeirão Preto, e apresentando uma rentabilidade de 5,96\% em uma média dos últimos 12 meses, uma taxa relativamente baixa de retorno, refletida pelo CDI. Por sua vez, na presente carteira analisou-se uma Letra de Crédito Agrícola do Banco Fibra (LCA), esta gerou no período de 12 meses um retorno de 6,14\%, também tendo por base seu rendimento em uma porcentagem do CDI, e obteve retorno parecido com os apresentados anteriormente.

O Fundo de Investimento usado como exemplo, gerido pelo ARX TARGET INSTITUICIONAL, fora analisado pelo período determinado e rendeu nos 12 meses um total de 5,37\%. Para o período, o fundo não apresentou grandes resultados, levando em consideração seu grau de risco que é maior que os produtos de renda fixa, acabou não sendo uma boa opção para o investidor, porém, o fundo foi apenas 
um de vários possíveis para a pessoa física ter em carteira, o que não o descarta como uma boa opção de investimento pensando em um prazo mais longo.

Quanto à parte da renda variável, sobre o mercado de ações, foram utilizados os seguintes ativos: Companhia Vale do Rio Doce que faz uso da sigla VALE3, a Companhia Petrolífera Brasileira ou Petrobrás que tem seu ativo negociado através da sigla PETR4 e o Banco do Brasil, este por sua vez é negociado com a sigla BBAS3 na Bolsa de SP (B3).

Figura 2 - Aplicações em ações

\begin{tabular}{|c|c|c|c|}
\hline TIPO/NOME DA APLICAÇÃO & AÇÕES / PETR4 & AÇÕES / VALE3 & AÇÕES / BBAS3 \\
\hline CLASSIFICAÇÃO CVM & RENDA VARIÁVEL & RENDA VARIÁVEL & RENDA VARIÁVEL \\
\hline NIVEL DE RISCO & ALTO & ALTO & ALTO \\
\hline APLICAÇÃO INICIAL & R\$ $2.930,00$ & $\mathrm{R} \$ 4.700,00$ & $R \$ 4.651,00$ \\
\hline RENTABILIDADE \% 12 MESES & $71,42 \%$ & $6,70 \%$ & $100,03 \%$ \\
\hline RENTABILIDADE \% 6 MESES & $14,40 \%$ & $1,42 \%$ & $13,46 \%$ \\
\hline CRÉDITO EM CONTA CORRENTE & D+2 & D+2 & D+2 \\
\hline ORGANIZAÇÃO & PETROBRÁS & $\begin{array}{c}\text { VALE DO RIO } \\
\text { DOCE }\end{array}$ & BANCO DO BRASIL \\
\hline
\end{tabular}

Fonte: Rico Corretora (2019b).

As ações da (VALE3) Companhia Vale do Rio Doce, por sua vez, neste período apresentaram uma valorização de apenas 1,43\%, tendo como fato a se considerar relevante, a tragédia ocorrida na cidade de Brumadinho, em janeiro de 2019 em que, uma barragem da Vale se rompeu, causando uma tragédia local e enfraquecendo a confiança dos investidores.

Após o ocorrido, as ações da companhia adotaram uma tendência lateral, não avançando muito neste período de tempo estudado. Somando com a insegurança de negociações externas, como por exemplo, China x EUA, a situação do papel foi estável, mas não muito positiva. Analisando o investimento de $\mathrm{R} \$ 5.000,00$, o investidor teve um lucro de R\$71,50 após os 6 meses com o papel, inferior aos demais produtos disponíveis na carteira.

Na (PETR4) Petrobrás, o papel obteve forte variação. Seu fechamento para cada ação no primeiro pregão do ano de 2019 foi de $\mathrm{R} \$ 23,54$, finalizando o período sendo negociado a $\mathrm{R} \$ 26,93$ no dia 28/06/2019. Desta forma, a companhia obteve uma valorização de 14,4\% nas suas ações. Para as ações do (BBAS3) Banco do Brasil, também se obteve uma valorização satisfatória, a negociação do papel iniciou-se com valor de $\mathrm{R} \$ 46,97$, e após o tempo da análise fechou o último pregão no dia $28 / 06 / 2019$ sendo negociada no valor de $\mathrm{R} \$ 53,29$. 0 papel da empresa obteve uma valorização de $13,46 \%$, um resultado muito positivo, destacando-se entre os melhores investimentos possíveis demonstrados no trabalho.

0 valor aplicado nos ativos foi igualmente distribuído com o valor de $R \$$ 5.000,00 para cada um deles, e mantiveram-se a partir da data de 02/01/19 até a data de 28/06/19, o que totaliza aproximadamente 6 meses. 0 índice BOVESPA, da bolsa de valores brasileira. Nota-se que houve uma alta interessante no período 
analisado, fechando a 91.012 pontos no primeiro pregão do ano, e no último pregão analisado fechou o pregão em 100.967 pontos. Uma alta de 10,94\% no seu índice em um período de apenas 6 meses.

Para a poupança, destacou-se a rentabilidade tradicional, conservadora. Como já havia comentado o autor Assaf Neto "No Brasil, o investimento mais popular é a poupança, caracterizada por ser puramente renda fixa, ela possui uma grande segurança no capital investido, porém com rendimentos limitados e geralmente baixos." Obteve-se uma taxa de 4,55\% ao ano, ao aplicar $\mathrm{R} \$ 5.000,00$ na poupança e retirar após um período de 6 meses, o investidor terá $\mathrm{R} \$ 5.113,75$, uma rentabilidade relativamente baixa de apenas $R \$ 113,75$, porém para a caderneta, não há imposto cobrado sobre o lucro. Nesta aplicação de 6 meses, na poupança, o investidor teria uma rentabilidade de 2,27\%, conforme Figura 3.

Figura 3 - Poupança

\begin{tabular}{|c|}
\hline POUPANÇA \\
\hline RENDA FIXA \\
\hline RISCO MUITO BAIXO \\
\hline RENTABILIDADE 6 MESES $2,27 \%$. \\
\hline
\end{tabular}

Fonte: Autores.

Para o Tesouro Selic 2025, houve um ganho levemente maior que o da poupança como afirmou o autor anteriormente "O Tesouro Selic é uma opção parecida com a poupança" (INFOMONEY, 2019), no caso de 6 meses, o imposto pago sobre o lucro ao retirar a aplicação seria de $22,5 \%$, totalizando um Imposto de Renda (IR) de $\mathrm{R} \$ 36,56$, desta forma o lucro do investidor passaria de $\mathrm{R} \$ 162,50$ para $\mathrm{R} \$ 125,94$. Se o investidor optasse por realizar a retirada entre 181 e 365 dias, esta taxa de IR seria reduzida para $20 \%$, sendo assim progressivamente, alcançando um investimento com prazo maior de 720 dias o IR seria de $15 \%$ sobre o lucro. 0 investidor teria após os 6 meses, retorno de 2,52\% após a retirada.

Figura 4 - Tesouro Selic 2025

\begin{tabular}{|c|}
\hline TESOURO SELIC 2025 \\
\hline RENDA FIXA \\
\hline RISCO MUITO BAIXO \\
\hline RENTABILIDADE 6 MESES 2,52\% \\
\hline
\end{tabular}

Fonte: Autores.

O CDB estudado foi da administradora (GMAC) Banco Chevrolet, e este obteve um retorno de 6,2\% em 12 meses, tendo base em 101\% do CDI. Com $\mathrm{R} \$ 5.000,00$, o investidor teria disponível na sua conta após 6 meses um montante de $\mathrm{R} \$ 5.153,00$, porém é necessário levar em consideração o IOF que seria pago para realizar o resgate, que possui a mesma taxa do Tesouro Selic, ou seja, 22,5\% sobre o lucro de operações iguais ou inferiores à 180 dias. Desta forma, o investidor pagaria $\mathrm{R} \$ 34,43$ de imposto na retirada desta aplicação, fazendo com que a rentabilidade do CDB fique muito prejudicada, restando como montante para o investidor no final dos 6 meses o valor de $\mathrm{R} \$ 5.118,57$ (em percentual daria 2,37\%). 
Figura 5- CDB GMAC 2020

\begin{tabular}{|c|}
\hline CDB GMAC 2020 \\
\hline RENDA FIXA \\
\hline RISCO BAIXO \\
\hline RENTABILIDADE 6 MESES $2,37 \%$ \\
\hline
\end{tabular}

Fonte: Autores.

Na Figura 6, pode-se analisar o andamento da taxa CDI nos últimos anos, notando que no ano de 2016 o rendimento era razoavelmente maior, o investidor poderia extrair um rendimento 111,4\% maior se comparar os anos de 2016 e 2018.

Figura 6 - Taxa CDI últimos anos

\begin{tabular}{|c|c|c|c|c|}
\hline \multicolumn{5}{|c|}{ TAXA CDI ÚLTIMOS ANOS } \\
\hline MÊS/ANO & 2019 & 2018 & 2017 & 2016 \\
\hline \% JANEIRO & 0,54 & 0,58 & 1,04 & 1,05 \\
\hline \% FEVEREIRO & 0,49 & 0,46 & 0,86 & 1,00 \\
\hline$\%$ MARÇO & 0,47 & 0,53 & 1,00 & 1,16 \\
\hline$\%$ ABRIL & 0,52 & 0,52 & 0,79 & 1,05 \\
\hline \% MAIO & 0,54 & 0,52 & 0,88 & 1,11 \\
\hline$\%$ JUNHO & 0,47 & 0,52 & 0,77 & 1,16 \\
\hline$\%$ JULHO & 0,57 & 0,54 & 0,76 & 1,11 \\
\hline$\%$ AGOSTO & 0,50 & 0,57 & 0,77 & 1,21 \\
\hline$\%$ SETEMBRO & 0,46 & 0,47 & 0,64 & 1,11 \\
\hline$\%$ OUTUBRO & & 0,54 & 0,64 & 1,05 \\
\hline$\%$ NOVEMBRO & & 0,49 & 0,57 & 1,04 \\
\hline$\%$ DEZEMBRO & & 0,49 & 0,54 & 1,12 \\
\hline$\%$ ACUMULADO ANO & 4,56 & 6,23 & 9,26 & 13,17 \\
\hline
\end{tabular}

Fonte: Toro radar Investimentos (2019).

A (LCI) Letra de Crédito Imobiliário que fora utilizada como exemplo tem como gestor o Banco Ribeirão Preto e tem sua rentabilidade baseada em $97 \%$ do CDI, esta apresentou um rendimento de 5,95\% para os últimos 12 meses, uma taxa relativamente baixa de retorno, refletida pelo CDI. Para o investidor aportar em LCI, ele não pagará IR sobre sua retirada, porém será necessário que espere no mínimo 180 dias para resgatar o investimento. Neste caso, se o investimento fosse de exatamente 6 meses, utilizando por base o rendimento anual de 5,95\%, a pessoa física teria como capital $\mathrm{R} \$ 5.147,00$, ou seja, um lucro de $\mathrm{R} \$ 147,00$ livre de imposto de renda. Em porcentagem, esta aplicação renderia nos 6 meses 2,94\%.

Figura 7 - LCI Banco Ribeirão Preto

\begin{tabular}{|c|}
\hline LCI BCO. RIBEIRAO PRETO \\
\hline RENDA FIXA \\
\hline RISCO BAIXO \\
\hline RENTABILIDADE 6 MESES $2,94 \%$ \\
\hline
\end{tabular}

Fonte: Autores.

Para o investimento em (LCA) Letra de Crédito do Agronegócio, coordenado pelo Banco Fibra S.A, o investidor conta com um retorno de 100\% do CDI, ou seja, com o investimento de $R \$ 5.000,00$, estariam disponíveis para saque $R \$ 5.151,50$, tendo como lucro $\mathrm{R} \$ 151,50$ livres de imposto de renda. Um lucro de 3,03\% no final dos 6 meses. Este investimento é muito parecido com o anterior, LCI, onde também não há IR sobre lucros, mas é necessário aguardar 180 dias, para ter o dinheiro e lucro disponíveis. 
Figura 8 - LCA BANCO FIBRA S.A.

\begin{tabular}{|c|}
\hline LCABANCO FIBRAS.A \\
\hline RENDA FIXA \\
\hline RISCO BAIXO \\
\hline RENTABILIDADE 6 MESES 3,03\% \\
\hline
\end{tabular}

Fonte: Autores.

O Fundo de Investimento ARX TARGET INSTITUCIONAL, em 12 meses gerou 5,37\%. 0 objetivo deste fundo de investimento é superar a taxa do CDI, porém isso não ocorreu, logo, não houve taxa de performance a ser calculada. Se houvesse, seria $20 \%$ sobre o valor que ultrapassasse os $100 \%$ do CDI. A taxa de administração do fundo pode variar de $0,9 \%$ a 1,35\% ao ano, sendo assim, fez-se uma média da taxa, cuja ficou em 1,13\% ao ano. Com o investidor realizando um aporte de $\mathrm{R} \$$ 5.000,00 no fundo, e aguardando o tempo da pesquisa que fora de 6 meses, ele teria um rendimento de $\mathrm{R} \$ 134,25$, porém é necessário realizar o desconto da taxa de administração. Sendo assim, R\$ 29,00 ficariam presos como taxa de administração do fundo, restando apenas o montante de $\mathrm{R} \$ 5.105,25$.

0 rendimento do fundo foi razoável, porém com a taxa de administração, este se tornou o pior investimento da carteira até agora, em 6 meses um lucro de apenas $\mathrm{R} \$ 105,25$ sobre os $\mathrm{R} \$ 5.000,00$ aplicados. Isso é uma valorização de $2,11 \%$ sobre o valor total. Se o investidor optasse pela retirada do valor, ainda pagaria IR de $\mathrm{R} \$ 23,74$, restando $\mathrm{R} \$ 81,51$ de lucro. 0 fundo se adequaria melhor para uma aplicação de longo prazo.

Figura 9 - Fundo ARX Target Institucional

\begin{tabular}{|c|}
\hline FUNDO ARX TARGET INSTITUCIONAL \\
\hline MULTIMERCADO/ VARIÁVEL \\
\hline RISCO MODERADO \\
\hline RENTABILIDADE 6 MESES 2,11\% \\
\hline
\end{tabular}

Fonte: Autores.

Para a Petrobrás, nota-se forte crescimento, iniciando sendo negociada ao valor de $R \$ 23,54$ e terminando negociada em $R \$ 26,93$, valorização de $14,40 \%$ no valor das ações da empresa. Segundo o autor, o mercado de ações é muito volátil “De 2002 até a crise de 2008, o mercado de ações no Brasil apresentou uma rentabilidade acima de 400\%" (NIGRO, 2018). Considerando o investimento de $\mathrm{R} \$ 5.000,00$ no período de $02 / 01 / 19$ à $28 / 06 / 19$, pode-se dizer que o investidor teria $\mathrm{R} \$ 5.720,00$ como valor total, se vendesse suas ações pagaria $\mathrm{R} \$ 108,00$ de IR sobre a operação, e restaria para o investidor $\mathrm{R} \$ 5.612,00$.

A partir da análise da empresa Vale, é possível notar que não houve um grande crescimento durante o período da análise, iniciando sendo negociada ao valor de $\mathrm{R} \$ 51,09$ e terminando o período de análise sendo negociada ao valor de $\mathrm{R} \$ 51,82$, uma valorização de 1,43\% no valor das ações da empresa. Desta forma, o investidor pagaria um IR de $\mathrm{R} \$ 10,73$ e teria lucro de $\mathrm{R} \$ 60,78$. Percebe-se uma variação brusca que ocorreu durante a tragédia de Brumadinho, que ocorreu em 25 de janeiro de 2019.

Nas ações do Banco do Brasil, o cenário foi positivo, visto que a empresa mesmo entre forte variação obteve uma valorização considerável de seus papéis, fechando o pregão do dia 02/01/19 em $\mathrm{R} \$ 46,97$ e finalizando o período de análise 
com suas ações valendo $\mathrm{R} \$ 53,29$, uma alta de $13,46 \%$. De acordo com os dados, o investidor aplicou o valor de $\mathrm{R} \$ 5.000,00$ e no final dos 6 meses teve a possibilidade de retirar, já descontado $15 \%$ sobre o lucro, o valor de $\mathrm{R} \$ 5.572,05$. 0 imposto pago na operação seria de $\mathrm{R} \$ 100,95$.

Ao analisar os tipos de investimentos percebeu-se que os investimentos de renda variável, embora tenham maior risco, foram os que mais se destacaram quanto a rentabilidade, ênfase para o papel do Banco do Brasil, com uma alta de 100,03\% em um período de apenas 12 meses. No período de análise, a ação atingiu a segunda posição com uma valorização de $13,46 \%$, perdendo para o papel da Petrobrás (PETR4) com uma alta de 14,40\%. Quanto à renda fixa, o investimento que mais se destacou em seu retorno de capital foi a LCA, que nos 6 meses analisados gerou um lucro de 3,03\% livres de imposto de renda.

\section{CONCLUSÃO}

Conforme mencionado ao longo do estudo, identificou-se que muitas pessoas buscam encontrar formas de aumentar seus ganhos e rendimentos, visto que seus salários muitas vezes não são suficientes para garantir seu futuro, levando em consideração a importância do uso consciente do dinheiro, mantendo seu consumo controlado, sem gastos supérfluos. Assim, e também com base em todas as informações expostas ao longo da pesquisa, destaque-se que o objetivo do presente artigo foi atingido, ou seja, foi possível apresentar uma análise do mercado financeiro brasileiro, de acordo as delimitações propostas para este estudo, apresentando estratégias, oportunidades e desafios para se buscar alcançar a excelência na gestão financeira.

De forma mais específica, ressalte-se que no contexto da gestão financeira, a referida excelência fica evidente a partir da apresentação dos pressupostos sobre aplicações financeiras e suas opções disponíveis. Também, acerca da análise de visões, comparações e oportunidades sobre a temática proposta com base em diversos autores considerados referência. Ainda, a partir do que foi apresentado sobre o mercado de ações, ativos de renda variável e suas particularidades.

Importante ressaltar também que o estudo apresentou subsídios de informações a partir da comparação entre diferentes ativos de produtos financeiros e suas nuances, sendo eles de renda fixa e variável, demonstrando a grande gama de opções que o investidor possui. E, finalmente, a apresentação para o entendimento da rentabilidade real, tomando por base as taxas aplicadas no período estudado, no qual se realizaram investimentos na caderneta de poupança, tesouro Selic, CDB, LCI, LCA, Fundo Multimercado e, o mercado de ações com a renda variável, utilizando como exemplo os ativos da companhia Vale do Rio Doce, companhia petrolífera Petrobrás e o Banco do Brasil.

Por fim, saliente-se que o "mercado financeiro" é possível para grande parte das pessoas físicas, desde que essas, busquem conhecimento para alocar seu capital, e que geralmente estes mercados não oferecem resultados negativos se forem pensados em longo prazo. Acrescente-se que o mercado de ações possui uma explicação complexa, visto que se separa por vários caminhos. A renda variável 
possui uma enorme volatilidade, transformando em dor de cabeça um investimento que seja pensado em curto prazo, mas que se demonstrou sendo rentável num pensamento de médio ou longo prazo. E, espera-se com base nas atividades de pesquisa realizadas, oferecer subsídios de informações relevantes para tornar a gestão financeira mais eficiente, tanto para pessoas físicas como jurídicas que atuem na referida área e conhecimento.

\section{LIMITAÇÕES E SUGESTÃO DE NOVOS ESTUDOS}

Para estudos futuros, sugere-se ampliar o nível de análises para períodos maiores, e/ou especificamente para o período que envolve o COVID-19. Como limitação do estudo, entende-se que o mesmo foi pensado, direcionado e executado com prioridade à pessoa física que possui interesse em aprender sobre o mercado financeiro.

\section{REFERÊNCIAS}

ABREU, Edgar Gomes; SILVA, Lucas. Sistema financeiro nacional. 1. ed. - Rio de Janeiro: Forense, 2017.

ASSAF NETO, Alexandre. Mercado financeiro. 12. ed. São Paulo: Atlas, 2014.

BACEN, Regimento interno do Banco Central do Brasil. 2019a. Disponível em: www.bcb.gov.br/content/acessoinformacao/Documents/re gimento_interno/RegimentoInterno.pdf. Acesso em: 12 nov. 2019.

BACEN, 0 que é o sistema financeiro nacional. 2019b. Disponível em: https://www.bcb.gov.br/estabilidadefinanceira/sfn. Acesso em: 15 nov. 2019.

BARONI, Marcos; BASTOS, Danilo. Guia Suno Fundos Imobiliários, Introdução Sobre Investimentos Seguros e Rentáveis. 1. ed. - São Paulo: Vivalendo, 2018.

BRITO, Osias. Mercado Financeiro: estruturas, produtos, serviços, riscos, controle gerencial. 2. ed. São Paulo: Saraiva, 2013.

BTG PACTUAL, 0 que são as LCIs. 2019. Disponível em: https://www.btgpactualdi gital.com/rendafixa/lci. Acesso em: 10 nov. 2019.

CERBASI, Gustavo. Investimentos Inteligentes: para conquistar e multiplicar o seu primeiro milhão. Rio de Janeiro: Thomas Nelson Brasil, 2008.

CVM, Sobre a CVM. 2019. Disponível em: http://www.cvm.gov.br/menu/acess o_informacão/institucional/sobre/cvm.html. Acesso em: 10 nov. 2019.

DESCHATRE, Gil Ari. Investimento em ações: para os momentos de crise e de crescimento. Rio de Janeiro: Thomas Nelson Brasil, 2009.

EASYNVEST, 0 que é uma corretora de valores. 2019. Disponível em: https://ajuda.easynvest.com.br/hc/pt-br/articles/226454147-0-que-é-uma-corretora-de-valores. Acesso em: 10 nov. 2019.

ELDER, Alexander. Aprenda a operar no mercado de ações; Tradução de Afonso Celso da Cunha Serra. Come intomy trading room. Rio de Janeiro: Elsevier, 2006.

FORTUNA, Eduardo. Mercado Financeiro. 20. ed. - Rio de Janeiro: Qualitymark, 2015.

GIL, A. C. Métodos e técnicas de pesquisa social. 5. ed. - São Paulo: Atlas, 1999. 
INFOMONEY, 0 que são os fundos de investimento. Disponível em:

https://www.infomoney.com.br/guias/fundos-de-investimento/. Acesso em: 10 nov. 2019.

INFOMONEY,0 que é o Tesouro Selic. 2019. Disponível em: https://www.i nfomoney.com.br/ondeinvestir/o-que-e-tesouro-selic/. Acesso em: 10 nov. 2019.

ITAU, Ações: 0 que são ações? 2019. Disponível em: https://www.itau.com.br /investimentos/acoes/. Acesso em: 4 nov. 2019.

LUQUET, Mara; ROCCO, Nelson. Guia Valor Econômico de Investimentos em Ações. 1. ed. - São Paulo: Globo, 2005.

LUQUET, Mara; ASSEF, Andrea. Você tem opções do que imagina: um guia para suas finanças pessoais. São Paulo: Saraiva: Letras \& Lucros, 2007.

MARTINS, Leandro. Aprenda a investir: saiba onde e como aplicar seu dinheiro. São Paulo: Atlas, 2008.

MINISTÉRIO DA ECONOMIA, Conselho Monetário Nacional - CMN. 2019. Disponível em: http://www.fazenda.gov.br/assuntos/cmn. Acesso em: 18 nov. 2019.

NIGRO, Thiago. Do mil ao milhão, sem cortar o cafezinho. 1. ed. Rio de Janeiro: Harper Collins, 2018. RICO CORRETORA, Qual a função do FGC? 2019a. Disponível em: https://blog.rico.co m.vc/fundogarantidor-credito-fgc. Acesso em: 10 nov. 2019.

RICO CORRETORA, Gráficos da renda fixa. 2019b. Disponível em: https://www.rico. com.vc/login/. Acesso em: 10 nov. 2019.

SEVERINO, A. J. Metodologia do trabalho científico. 21. ed. - São Paulo: Cortez, 2000.

SICREDI, Letra de crédito do agronegócio. 2019. Disponível em: https://www.sicr edi.com.br/html/para-voce/investimentos/letra-credito-agronegocio/. Acesso em: 15 nov. 2019.

SILVA, E.; MENEZES, E. Metodologia da pesquisa e elaboração da dissertação. 4. ed. - Florianópolis: UFSC, 2005.

TESOURO DIRETO, 0 que é o Tesouro Direto. 2019. Disponível em:

https://www.tesourodireto.com.br/conheca/conheca-o-tesouro-direto.htm. Acesso em: 11 nov. 2019.

TORO RADAR INVESTIMENTOS. 0 que é taxa CDI? 2019. Disponível em:

https://www.tororadar.com.br/investimentos/cdi-taxa-o-que-e-rendimento. Acesso em: 8 nov. 2019. 